\title{
O valor do meio ambiente segundo Peter Singer
}

\author{
Igor Zanoni Constant Carneiro Leão* \\ Denise Maria Maia*
}

RESUMO - O texto apresenta uma mostra do pensamento do filósofo ético Peter Singer, um dos mais importantes pensadores sobre questões como meio ambiente e direitos dos animais, propondo uma forma sustentável de vida na atualidade.

Palavras-chave: Meio ambiente. Ética contemporânea. Sustentabilidade.

A economia e a ética confluem em diversas áreas relevantes na atualidade, uma das quais são os direitos do meio ambiente. Este problema foi abordado pelo filósofo australiano Peter Singer em seu importante livro Ética Prática. Este é um problema que diz respeito ao nosso dia a dia e que tem ganhado importância nos últimos 50 anos. Trata-se de um problema ético relevante na medida em que um ser racional deve levá-lo em conta considerando quais são as responsabilidades que temos para com o meio ambiente e para o bem-estar das gerações futuras que herdarão a Terra.

Singer é um filósofo utilitarista. Para ele, na medida em que alguém vive de acordo com padrões éticos, deve justificá-los não apenas em termos de interesse pessoal, mas demonstrando que os atos com base no interesse pessoal são compatíveis com princípios éticos referentes a um público maior. Dentro da tradição utilitarista existe o axioma de que na decisão de questões morais cada qual valha por uma e nenhuma por mais de uma. Nesse sentido a ética tem um caráter universal, devendo-se atribuir aos interesses alheios o mesmo peso que atribuímos aos nossos.

Portanto, para o autor os juízos éticos extrapolam nossas preferências e aversões, pois a ética exige que se chegue a um juízo universalizável do ponto de vista do que Adam Smith denominava o espectador imparcial ou o observador ideal. Os interesses de uma pessoa não podem contar mais que os interesses de uma outra. A preocupação natural de alguém de que seus interesses sejam levados em conta deve ser estendida aos interesses dos outros. Uma decisão ética leva em conta como condutas possíveis em uma ocasião afetarão os meus interesses e o que as pessoas desejam como fazendo parte dos seus interesses.

\footnotetext{
* Doutor em economia pela Universidade Estadual de Campinas. É professor do Departamento de Economia da Universidade Federal do Paraná. Endereço eletrônico: igorzaleao@yahoo.com.br.

** Doutora em educação pela Universidade Federal de Minas Gerais. É professora do Departamento de Economia da Universidade Federal do Paraná. Endereço eletrônico: denimaia@ufpr.br.
} 
Deve-se, pois, escolher um curso de ação que tenha as melhores consequências para todos os afetados, depois de examinar todas as alternativas possíveis. Essa postura utilitária é uma base inicial na qual chegamos a universalizar a tomada de decisões com base no interesse ético. Há outras posições éticas baseadas na teoria dos direitos, da justiça, do caráter sagrado da vida e assim por diante. Mas até que tenhamos boas razões para extrapolar o utilitarismo e aceitar princípios ou ideais morais vale a pena levar em conta as posições utilitaristas.

Em Ética Prática, Peter Singer faz uma aplicação da ética ou da moralidade à abordagem de questões práticas como o tratamento dispensado às minorias étnicas, a igualdade para as mulheres, o uso de animais em pesquisas e para a fabricação de alimentos, a preservação do meio ambiente, o aborto, a eutanásia e a obrigação dos ricos de ajudar os pobres. Neste texto vamos relembrar sua discussão sobre a preservação do meio ambiente.

O autor começa lembrando a tradição ocidental ante à natureza, na qual o homem é o centro do universo moral ou reúne quase sempre a totalidade das características moralmente significativas deste mundo. Já no relato bíblico da criação no livro de Gênesis pode-se ver a concepção hebraica do lugar especial ocupado pelos seres humanos no plano divino diante da natureza. A ideia é de que o homem herdou um domínio sobre a natureza e todos os seres que se movem sobre a Terra. Embora muitos cristãos afirmem que a concessão desse domínio não deve ser vista como uma licença para fazermos tudo o que quisermos com as outras coisas vivas, mas como uma orientação para cuidarmos delas em nome de Deus, essa interpretação não encontra muito respaldo no Antigo Testamento, que em várias passagens afirma a entrega por Deus ao homem de tudo o que vive sobre a Terra e do respeito e temor devido por todos os seres ao homem. Essa tradição perpassa também o novo testamento e mesmo os padres da Igreja, como Santo Agostinho, e por escolásticos medievais, como Santo Tomás de Aquino. Para este, seguindo uma orientação ao mesmo tempo bíblica e aristotélica, não há possibilidade alguma de se pecar contra os animais ou contra o mundo natural.

Assim, de acordo com a tradição ocidental dominante, os seres humanos são os únicos membros moralmente importantes do mundo e a natureza não tem nenhum valor inerente. A destruição de plantas e animais não pode configurar um pecado a menos que através dela façamos mal aos seres humanos. Essa tradição, porém, não exclui o cuidado com a preservação da natureza desde que ele esteja associado ao bem-estar humano. Isto pode embasar uma posição contrária à energia nuclear ou à poluição, o uso de gases prejudiciais à camada de ozônio, à queima de combustíveis fósseis e à destruição de florestas, entre outras questões ambientais relevantes. Dessa forma, a derrubada de uma floresta antiga, por exemplo, deve levar em conta plenamente o valor das florestas para as gerações que habitarão o planeta num futuro próximo 
ou distante. Esse valor está ligado à importância estética ou biológica da floresta e se torna maior à medida que as grandes extensões de paisagem natural se tornam mais raras e diminuem as chances de se fazer uma seleção com base na razão das principais formas de terras virgens a serem preservadas.

Temos indicações de que as futuras gerações vão apreciar a natureza com o apreço atual pela natureza, sobretudo nos países que superaram a pobreza e a fome e têm poucas terras virgens remanescentes em seu território. Se as futuras gerações forem capazes de atender às necessidades básicas da maioria das pessoas, estas deverão valorizar a natureza pelos mesmos motivos que nós. Os valores estéticos contam pois, para muitos, as florestas são a fonte dos maiores sentimentos de plenitude estética, talvez mais intensos do que experimentamos em um grande museu como o Louvre, por exemplo. Isto significa que através da nossa preservação das áreas verdes podemos dar às gerações futuras uma oportunidade de criar uma cultura que leve em conta a vida em sintonia com a natureza. Esta é uma forma de não lesar as futuras gerações assim como gerações passadas nos lesaram ao extinguir animais como o Dodó e outros.

Tudo isto significa que uma ética centrada no homem pode ser a base de argumentos favoráveis aos valores ambientais. Como afirma Peter Singer:

Tal ética não implica que o crescimento econômico seja mais importante do que a preservação da natureza; pelo contrário, é bastante compatível com uma ética centrada no homem o ponto de vista que vê o crescimento econômico baseado na exploração dos recursos não renováveis como algo que traz benefícios à presente geração, e talvez a mais uma ou duas gerações, mas a um preço que terá de ser pago por todas as gerações que vierem depois. (SINGER, 1993).

Todavia, a limitação a uma ética centrada no ser humano constitui um erro.

É arbitrário defender o ponto de vista de que só os seres humanos têm um valor intrínseco. Não é possível negar que se existe o valor nas experiências humanas conscientes, deve-se também encontrar valor pelo menos em algumas experiências dos seres não humanos. Uma coisa tem um valor intrínseco se for boa ou desejável por si mesmo e não como uma forma de obtenção de algum outro objetivo. Assim, o dinheiro tem para nós um valor instrumental, mas a nossa própria felicidade tem um valor intrínseco, pois a desejamos por si mesma. Se examinarmos um problema como o da construção de uma represa em um rio, tomando a decisão exclusivamente com base nos interesses humanos teríamos de confrontar as vantagens econômicas da represa com a perda para os que acham o valor estético ou científico das matas para os homens de hoje e do futuro. Se levarmos em conta outros interesses além dos humanos, teremos de pensar nos animais que vivem na área a ser inundada, que provavelmente morrerão 
afogados ou de fome, sofrimento ao qual não se deve atribuir uma importância menor do que se abatesse sobre seres humanos. Neste ponto é importante examinar o que tem sido afirmado a respeito de se levar a ética além dos seres sencientes.

A posição do autor traça os limites das considerações morais que dizem respeito a todas as criaturas sencientes. Assim, a inundação das velhas florestas, a possível perda de uma espécie, por exemplo, são fatores que só devem ser levados em conta na medida em que exerçam um efeito adverso sobre criaturas sencientes. Levar uma ética além dos seres sencientes é uma tarefa difícil. Uma ética baseada nos interesses das criaturas sencientes pode ser estabelecida, pois estas têm vontades e desejos, o que nos dá uma orientação em relação ao que talvez fosse a coisa certa a se fazer. Entretanto, não há nada que corresponda ao que deve ser uma árvore morrendo porque suas raízes foram inundadas. Pode-se perguntar onde encontrar valor se abandonamos os interesses de criaturas sencientes como nossa fonte de valor.

Quando se trata de coisas vivas a resposta é facilmente encontrada, pois sabemos o que é bom ou mau para as plantas de nosso jardim ou de qualquer floresta ou região inculta. Entretanto, existe um problema aí, pois sem interesses conscientes a nos orientar, não temos como avaliar bem as importâncias relativas que devem ser atribuídas às diferentes formas de vida. Se formos além, o limite entre objetos naturais vivos e inanimados fica ainda mais difícil de defender. $\mathrm{O}$ autor se pergunta se seria pior abater uma velha árvore do que destruir uma bela estalactite que levou muito mais tempo para atingir sua forma atual. Há pensadores, como Albert Schweitzer, que usam a expressão "respeito pela vida”, que também é defendida por filósofos contemporâneos como Paul Taylor. Para ele, toda coisa viva está em busca do seu próprio bem, da sua própria forma, o que nos leva a vê-las da mesma maneira que vemos a nós, tornando-nos aptos a atribuir à sua existência o mesmo valor que atribuímos a nós. Contudo, a linguagem desses filósofos é metafórica, pois se as plantas não são conscientes não podem ter nenhum comportamento intencional, assim como um rio não tem ao buscar o mar. Dessa forma, não é óbvio por que devemos ter mais respeito por uma árvore do que por uma estalactite, por um organismo unicelular do que por uma montanha.

Singer passa neste ponto a discutir a chamada "ecologia profunda". Segundo seus fundadores, há um pensamento ecológico superficial circunscrito à estrutura moral tradicional através da qual o empenho em preservar a natureza tornaria possível às pessoas continuarem a desfrutar dos seus prazeres. Ao contrário, os ecologistas profundos desejariam preservar a integridade da biosfera por si mesma, independente dos possíveis benefícios que pudessem advir para os seres humanos. A ética do respeito pela vida enfatizando os organismos vivos individuais é substituída por uma ética que assume o valor das espécies, sistemas ecológicos e até 
a biosfera como um todo. A ecologia profunda, portanto, refere-se não só à vida, mas também a coisas inanimadas como rios, paisagens e ecossistemas. Supõe-se uma igualdade biocêntrica, isto é, de que na biosfera todas as coisas têm o mesmo direito de viver e florescer enquanto partes de um todo interligado no qual todos os organismos e todas as entidades da ecoesfera são iguais em termos de seu valor intrínseco.

Para Peter Singer coloca-se a pergunta: se todas as coisas vivas e mesmo não vivas são todas parte de um todo inter-relacionado, de que modo isto determina que todos tenham o mesmo valor intrínseco? Pode-se pensar numa resposta: todas as coisas vivas têm um papel a desempenhar num ecossistema do qual dependem para a sua sobrevivência. Entretanto, essa resposta nada diz sobre o papel do indivíduo para a sobrevivência do ecossistema como um todo. Em segundo lugar, o fato de todos os organismos serem parte de um todo inter-relacionado não indica que todos tenham um valor intrínseco, muito menos um valor intrínseco equivalente. Portanto, a ética da ecologia profunda não oferece resposta a perguntas sobre o valor das vidas de seres vivos individuais.

Pode-se pensar, contudo, em valores da ética ecológica desse tipo ligados a alguma forma de holismo, significando que a espécie ou o ecossistema não são apenas um conjunto de indivíduos, mas na verdade uma entidade em si. Assim, os interesses de uma espécie ou de um ecossistema devem ser levados em conta juntamente com os interesses individuais nas deliberações morais. Embora atraente, essa ideia não basta para que se possa afirmar que árvores, espécies e ecossistemas tenham interesses moralmente significativos. Para isso, seria preciso mostrar que a sobrevivência ou a realização desse tipo de individualidade tem um valor moral, independentemente da sua importância para a manutenção da vida consciente.

Isto indica que deve-se colocar uma linha divisória entre as criaturas sencientes e as não sencientes como uma base mais sólida para a demarcação de um limite importante na consideração de seu interesse moralmente significativo. Todavia, essa rejeição da ética básica da ecologia profunda não significa que o argumento a favor da preservação da natureza não seja forte. Apenas significa que devemos nos restringir aos argumentos baseados nos interesses das criaturas sencientes presentes e futuras, humanas e não humanas, o que basta para sustentar que o valor da preservação do que resta de regiões naturais significativas excede em muito os valores econômicos obtidos através da sua destruição.

Singer passa nesse ponto a desenvolver sua própria ética ambiental. Ele parte do princípio de que o "conjunto de virtudes éticas louvadas e o conjunto de proibições éticas adotadas pela ética das sociedades específicas vão sempre refletir as condições sob as quais elas devem existir e atuar, para que possam sobreviver." Caso contrário, essa sociedade deixaria de existir. 
Hoje contamos com uma ameaça nova, distinta das conhecidas por agrupamentos humanos mais antigos, à nossa sobrevivência:

A proliferação de seres humanos, aliada aos subprodutos do crescimento econômico, é tão capaz de varrer do mapa a nossa sociedade quanto o foram as velhas ameaças - e não apenas a nossa sociedade, mas todas as outras. Não se desenvolveu ainda nenhuma ética capaz de enfrentar essa ameaça. Alguns dos princípios éticos de que dispomos são exatamente o contrário daquilo que precisamos. O problema é que, como já vimos, os princípios éticos mudam lentamente, e o tempo que temos para desenvolver uma nova ética ambiental é curto. Tal ética consideraria cada ação prejudicial ao meio ambiente eticamente duvidosa, e francamente errada toda e qualquer ação que fosse desnecessariamente prejudicial. (SINGER, 1993, p. 300).

Assim, essa ética ambiental privilegiaria o aproveitamento e a reciclagem de recursos, vendo como negativos o consumo e a extravagância desnecessários. Essa ética incentivaria a consideração dos interesses de todas as criaturas sencientes, inclusive daquelas que habitarão o planeta num futuro distante. Ela inclui uma estética da apreciação dos lugares naturais não devastados pelo homem. Por outro lado, essa ética desestimula a existência das grandes famílias nas grandes e pequenas cidades. Uma ética ambiental também rejeita os ideais de uma sociedade materialista que mede o sucesso pelo número de bens de consumo acumulados por alguém. Esse sucesso seria avaliado em termos do desenvolvimento das aptidões individuais e da verdadeira conquista da satisfação e realização.

Ao mesmo tempo, incentiva a frugalidade como parte das medidas para diminuição da poluição e para a certeza de reutilização de tudo o que for passível de reutilização. Pode-se mesmo chegar aí a questionar a própria ideia de consumir produtos desnecessários. Pode-se também proceder a um reexame do que consideramos extravagância. A madeira proveniente de uma floresta tropical é extravagante, pois o valor a longo prazo dessa floresta é muito maior do que os usos aos quais se destina a madeira. Da mesma forma são extravagantes os produtos de papel descartável, dar um passeio de automóvel no campo, viagens desnecessárias e mesmo consumir carne de boi, de porco e de aves. Quase 40\% dos grãos no mundo são usados na alimentação dos animais. Existem três vezes mais animais domésticos do que seres humanos na Terra, pelo menos à época em que o livro foi publicado. Sentimos apreensão com o número de bebês que nascem nas partes mais pobres do mundo e ignoramos a imensa proliferação de animais de corte. Há um prodigioso desperdício de grãos que alimentam os animais criados para o consumo humano.

Além disso, o intenso uso de energia exigido pelos métodos utilizados nas fazendas atuais responde pelo consumo de imensas quantidades de combustíveis fósseis. Os fertilizantes 
químicos usados para a produção nessas fazendas produzem óxido nitroso, um dos gases responsáveis pelo Efeito Estufa. Também se perde florestas com a proliferação dessas fazendas. O gado libera na atmosfera grande quantidade de metano, mais poluente que o dióxido de carbono. Há, portanto, a necessidade de uma alimentação baseada em grande parte em legumes e cereais.

A perspectiva de incerteza da sobrevivência do planeta como ambiente necessário à vida da espécie humana resulta tambem na preocupação crescente de traduzir de forma mensurável as consequências das intervenções e ações concretas da interação homem/natureza. Para tratar das considerações sobre a proteção e conservação do meio ambiente, avançam, embora com lentidão, várias propostas conceituais, como da sustentabilidade e do desenvolvimento sustentável, que visam ampliar a consciência ambiental e orientar a adoção de instrumentos de gestão nos processos de decisão nos mais diversos cenários. O compromisso ético ganha nova dimensão. Objetivos econômicos e ambientais já são analisados para além da eficácia do uso dos recursos na produção, comercialização e consumo. O bem-estar da população e a competitividade mercadológica não podem mais dar as costas para a depreciação do capital natural.

A limitação e precariedade do PIB como medida do desempenho econômico hoje têm servido para incorporar e aprofundar outras discussões conceituais trazidas nas últimas décadas pelo tema do desenvolvimento sustentável. Esforços de compatibilização de estatísticas ambientais com as atividades econômicas estão focados na depleção de recursos minerais, emissão de poluentes industriais e perda de recursos madeireiros. Os problemas metodólogicos e a escassez de informações estatísticas são gradualmente equacionados para considerar a perda de ativos não produzidos, tanto em quantidade quanto em qualidade. Do mesmo modo, identificam-se esforços em mensurar os custos para restaurar os recursos naturais de fluxo, como água e ar, dos danos e da contaminação decorrentes do crescente nível e padrão de atividades econômicas. Assim as "contas ambientais" pretendem construir agregados com base em critérios ambientais, como o PIB verde e o PIB sustentável, embora ainda sejam iniciativas muito tímidas para a intensidade dos acontecimentos atuais.

A construção desses indicadores incorpora preocupações com o bem-estar das pessoas e a paz no mundo. O início do século foi brindado pelo relatório da Comissão Stiglitz, onde o indivíduo está no centro da análise. O impacto do PIB verde como indicador do crescimento econômico com suas respectivas consequências ao meio ambiente fez o governo chinês recuar da proposta de implementá-lo em 2007 por revelar-se politicamente inaceitável, como de crescimento zero. O PIB sustentável por sua vez amplia o processo de cálculo com outros parâmetros, avançando inclusive para aspectos mais subjetivos, como as condições de vida urbana, a 
cultura e a convivência socioambiental.

A conclusão do artigo é:

A ênfase na frugalidade e numa vida mais simples não significa que uma ética ambiental seja contrária ao prazer, mas sim que os prazeres que ela valoriza não provêm do consumo exagerado. Pelo contrário, eles provêm de calorosas relações pessoais e sexuais, do fato de se estar ao lado dos filhos e dos amigos, das conversas, dos esportes e das diversões que estejam em harmonia com o meio ambiente, em vez de causar-lhe danos, dos alimentos que não se baseiam na exploração de criaturas sencientes, nem resultam na destruição da Terra. De todos os tipos de atividades e trabalhos criativos e (com o devido cuidado de não danificar exatamente aquilo que se valoriza) da apreciação dos lugares ainda não arrasados deste mundo em que vivemos. (SINGER, 1993, p. 304).

Estas ideias constituem uma ética mínima de preservação ambiental e podem ser consideradas na constituição de uma definição de desenvolvimento sustentável. Este conceito tem implicações ecológicas, sociais e econômicas. Todavia, ele é muito impreciso, na medida em que para ser pensado em toda a sua radicalidade, implicaria numa profunda transformação do mundo em que vivemos.

\section{REFERÊNCIAS}

Planeta Sustentável. Felicidade também é riqueza. Diponível em: $<$ http://planetasustentavel.abril.com.br/noticia/desenvolvimento/comissao-stiglitz-sen-fitoussi-sarkozy-novo-pib499171.shtml>.

KLINK, C. Quanto mais quente melhor? Desafiando a sociedade civil a entender as mudanças climáticas. São Paulo: Peirópolis, 2007.

ODED GRAJEW COMENTA: PIB e Desenvolvimento Sustentável. Disponível em: <http://www1.ethos.org.br/EthosWeb/pt/4081/servicos_do_portal/noticias/itens/oded_ grajew_comenta_\%E2\%80\%9Cpib_e_desenvolvimento_sustentavel $\%$ E2\%80\%9D_.aspx>.

SINGER, P. Ética prática. São Paulo: Martins Fontes, 1993. 